\title{
LA CASA DELS SENYORS D'AYERBE, D'ORIGEN REIAL
}

\author{
Maria-Mercè Costa
}

Dels dos fills del rei Jaume I i de Teresa Gil de Vidaurre, el més gran, Jaume, obtingué la senyoria de Xèrica i restà vinculat al regne de València; mentre que el segon, Pere, fou fet senyor d'Ayerbe i fundà una petita dinastia que durà, almenys en la seva branca legítima principal, poc més de mig segle. Ha estat molt discutida la mateixa legitimitat dels dos germans, conseqüència de la mena de misteri que ha embolcallat sempre la unió de llurs pares. No és aquest el moment d'endinsar-nos en consideracions sobre aquest punt, al qual pensem dedicar, en un altre lloc, una extensió que no tindria una cabuda pertinent en el present treball. Ens disposem, ací, a intentar conèixer l'evolució de la familia d'Ayerbe, especialment a través dels documents. I, per això, comencem per establir la legitimitat de Jaume i de Pere, atenintnos a la declaració expressa de Jaume 1, generalment acceptada pels historiadors.

El rei dictà el seu darrer testament el 26 d'agost de 1272 , a Montpeller. I féu donació d'una bona sèrie de possessions als dos fills que havia tingut legítimament, deia, de Teresa; i que ells, d'alguna manera, ja tenien. Més encara, els atorgava el dret de successió a la corona en el cas que vinguessin a mancar, també successivament, els infants fills seus i de la reina Violant. Cal notar que, d'aquesta concessió, el rei no en féu participar cap 
dels seus fills il·legitims, Després d'això, ben pocs dubtes poden restar sobre la legitimitat de Jaume i de Pere. Les possessions corresponents a Pere, segons el testament, foren les següents, algunes d'elles no ben identificades: Ayerbe, Luesia, Agüero, Liso, Artaso, Castejón de Siesto, Bureta, Azuer, Cabañas i Boquiñeni'.

\section{PERE (I) D'AYERBE}

Podríem creure que Pere va néixer vers el 1257 si entenem literalment la donació del castell i vila de Flix feta el 18 d'agost d'aquell any per Jaume I a Teresa i els seus fills. Si no ho entenguéssim com a referència genèrica a una possible descendència futura de Teresa, hem de concloure que Pere ja era nat ${ }^{2}$. La primera notícia clara de la seva existència és del 2 de gener de 1258 , quan, juntament amb la seva mare, rebia com a heretat franca els castells d'Arcos, Zancarés i Peña de Ahija (segons interpretació de Huici), en el regne de València. Si Pere moria sense descendents, l'heretat passaria a un possible germà seu que pogués encara néixer i, si no en naixia cap, seria per al germà gran, Jaume de Xèrica ${ }^{3}$. De la mateixa manera caldria fer-ho amb les noves heretats, Suera i Fanzara, del mateix regne, que el rei atorgà a Pere el 9 d'octubre de 1259 i, una segona vegada, el 5 d'abril de 1260 . Totes aquestes concessions foren confirmades per l'infant Pere, el futur Pere el Gran, el 10-XII-12604. No hem pogut

1 ACA (Arxiu de la Corona d'Aragó), C (Cancelleria), pergamins Jaume 1, 2126. J. Zurita, Anales de la Corona de Aragón, Saragossa 1668, llibre III, cap. 101. Id. Indices rerum ab Aragoniae regibus gestarum ab initiis regni ad annum MCDX, Saragossa 1578, pp. 158-159. F. DiACO, «Anales del reyno de Valencia», I, València 1613, fol. 381 .

${ }^{2}$ ACA, C, r. 9, f.22.

${ }^{3}$ Arxiu del Regne de València, Real Justicia, t. XXIV, f.355. A. Huıc, «Colección diplomática de Jaime I el Conquistador», II, València 1919, p. 157, núm. 700.

${ }^{4}$ ACA, C, r.11, f.159; pergs. Jaume I, 1602 i 1643. J. Soler y PALET, «Un aspecte de la vida privada de Jaume In, I Congrés d'Història de la Corona 
trobar les concessions originals d'Ayerbe, Luesia, Agüero i Bureta, confirmades també el 1260 i ratificades en el testament reial.

El 1264 se suscità una qüestió amb els infançons de Luesia, els quals al-legaven contrafur en el fet de la concessió del lloc a Teresa i el seu fill Pere. El litigi seguia encara el 1272, sense que en poguem deduir clarament ni els motius ni el desenvolupament del cas. Sospitem, però, que hi havia una relació amb la reclamació que feren els rics homes d'Aragó, a les Corts de Saragossa del 1264, contra la concessió de terres, en qualitat d'honor, als fills de Teresa en perjudici dels mateixos reclamants. El rei havia començat per defensar la seva llibertat de repartir les seves heretats pròpies com a honors, però davant la insistència dels nobles finalment hagué de prometre que no donaria res més, amb tal caràcter, a aquells dos fills seus ${ }^{5}$.

Dels primers anys de Pere, a part de les donacions, sabem, per Diago, que ell i Jaume havien estat educats per Gil Ximénez de Segura, pare del que fou bisbe de Sogorb, Pere Ximénez de Segura ${ }^{6}$.

Pere d'Ayerbe, com tants d'altres nobles, tingué diverses cavalleries per les quals havia de prestar servei feudal al rei quan això li fos requerit. El 1270 constaven les següents: sis cavalleries a Sos, divuit a Pina amb el seu peatge, dues a Alcubierre, dues a Robres i dues a Loarre, amb la perspectiva d'obtenir-ne també a Bolea, lloc que en aquell moment es trobava empenyorat. En una relació del 19-IX-1272, les de Bolea resten encara pendents $\mathrm{i}$ les dues de Robres s'han canviat per una a Alpuente i una altra a Magallón?.

Malgrat tot, hi ha unes darreres concessions de Jaume I al seu

d'Aragó, II, Barcelona 1913, pp. 549-552. No podem admetre, pel que ja hem vist, que, com diu Soler i Palet, fos del 1259 la primera noticia d'un fill de Teresa. Com tampoc, la suposició apuntada per R. CHABরs («Doña Teresa Gil de Vidaure», El Archivo VI, València 1892, p. 26), que Pere fos nat més tard del 1260 , per tal com no figura en la donació de la Saidia feta al seu germà Jaume (Huicl, op. cit., III, València 1922, p. 131, núm. 1113).

${ }^{5}$ ACA, C, r.12, f.143; r.21, f.139v. Zurita, Anales, 11 . III, c.66 i 67.

${ }^{6}$ Disco, op cit., fol. 383 .

${ }^{7}$ ACA, C, r.18, ff. $7,35 v$; r.23, f.80v. 
fill Pere i són les de Luesia, Agüero, Rosel, Azuer, Boquiñeni i Acín, aquesta comprada per Teresa, com a heretats lliures, és a dir, sense prestació de serveis de cap mena ${ }^{8}$.

La primera vegada que veiem Pere convocat a prestar servei feudal fou el 9 de novembre de 1270: es presentaria el dia de Pasqua següent en el lloc on seria el rei i que li seria comunicat amb el temps degut. Fou cridat novament el 16-X-1271 per al gener de 1272; la data del 5 de gener i el lloc de Luna li foren comunicats el desembre. Es tractava d'ajudar el rei en la lluita contra Artal de Luna?.

En canvi, sense notícia de cap crida especial, Pere i el seu germà Jaume apareixen, el 1273, amb la seva gent a la frontera de Múrcia disposats a defensar-la contra els sarraïns ${ }^{10}$.

Per tal que els nobles, i, entre ells, Pere, no poguessin dir que no eren avisats a temps, el 16-III-1274 el rei els ordenà que es preparessin amb cavallers, cavalls i armes, que ja els diria més tard on caldria anar. La data de la cita s'anà ajornant i el lloc també resultà variable, de Lleida a Barcelona, i a mig agost. L'afer, aquesta vegada, era la submissió de la noblesa catalana, especialment de Ramon de Cardona. Però sembla que molts dels convocats no es presentaren i el país en sortí perjudicat" ${ }^{11}$. El servei reial calia, sovint, prestar-lo incondicionalment, sense deturar-se a pensar quina guerra podia haver-hi en el moment de la crida. Aixi es veu en la crida del 15-1X-1274: Pere i els altres

${ }^{8}$ ACA, C, r.20, f. 276.

${ }^{9} \mathrm{ACA}, \mathrm{C}, \mathrm{r} .18, \mathrm{ff} .13,82 \mathrm{v}, 85 \mathrm{v}$. Artal de Luna tenia qüestions amb els habitants de Zuera. Convocat a Corts, no s'hi presentà. El rei es mogué contra ell, li embargà els béns i l'exilià per cinc anys. (Zurıta, Anales, 11. III, c.76 i 80 ).

10 Zurita, Anales, 11. II, c.84. A. Bnllesteros-Beretta, Alfonso $X$ el Sabio, Barcelona 1961, p. 669. G. Escot Ano, Década primera de la historia de la insigne y coronada ciudad y reyno de Valencia, $1^{\text {a }}$ part, València 1611, 11. III, c. XI, col.534/3.

"ACA, C, r.18, ff. $65,65 \mathrm{v}, 66 \mathrm{v}, 67,67 \mathrm{v} ; \mathrm{r.23}$, ff. 22,23 . Huicl, op. cit., III, p. 450 , núm. 1451 i p. 453 , núm. 1456. El vescomte de Cardona al-legava diversos greuges rebuts i posava dificultats a complir certs manaments reials. Jaume I, en nom dels Usatges, li embargà els feus. (Zurita, Anales, 11. III, cc. $66,73,84,85,88$ ). 
havien de trobar-se a Montsó, a mitjan octubre, i el rei ja els donaria instruccions. Foren cridats novament el març del 1275, per reunir-se a Lleida, tres setmanes després de Pasqua. A Lleida també es reuniren les Corts, l'octubre següent; entre els convocats hi figurava Pere d'Ayerbe ${ }^{12}$.

Ja mort el rei, Pere es veié embolicat, amb la seva mare i el seu germà, en un plet que promogué Bernat Guillem d'Entença per la possessió de la vila d'El Toro, la qual pertanyia, de fet, a la casa de Xèrica ${ }^{13}$. Possiblement el cas no entrava dins els interessos particulars de Pere; no obstant, ell i els seus dos familiars més propers actuen junts en diverses ocasions que devien conceptuar com d'interès comú. Així, el 1272, Jaume i Pere havien donat el seu consentiment per a la venda que féu la seva mare, Teresa, de la seva heretat de Subiza, per 4.200 morabetins d'or, al rei Enric I de Navarra ${ }^{14}$. El mateix any, diu Miret i Sans, mare i fills feien remissió al monestir de Piedra d'una suma de diners que li havien reclamat en indemnització per un lliurament indegut de bestiar del monestir en les seves terres ${ }^{15}$.

Aquests dos fills de Jaume I devien posseir el temperament impetuós de molts nobles de l'època. El rei Pere el Gran, una vegada, els hagué d'amonestar per una exigència abusiva del dret de cena en Ilocs dels ordes del Temple i de l'Hospital $i$ els obligà a la deguda restituciói ${ }^{16}$. No obstant, Pere d'Ayerbe estigué sovint al costat del seu reial germà. Quan Pere el Gran es trobà a Campillo, entre Àgreda i Taraçona, amb Alfons X de Castella i signaren un conveni d'amistat extensiu als seus hereus, el 27 III-1281, tot i acordar secretament la conquesta i repartiment de Navarra, Pere d'Ayerbe hi fou present i fou un dels nobles que

${ }_{12}$ ACA, C, r. 18, f.61v; r.17, f.7; r.23, f.33.

${ }_{13}^{13}$ ACA, C, r. 38, f. $110 \mathrm{v}$.

${ }^{14}$ Archivo General de Navarra, Comptos, caj. 3, núm. 50. J.R. CAstro, Archivo General de Navarra. Catálogo de la sección de Comptos. Documentos. I, Pamplona 1952, p. 193, núm. 399. F. DE SAGARRA, «Sigillografia Catalana», 1, Barcelona 1916, p. 253, núm. 241.

15 J. Miret I SANs, «Itinerari de Jaume I "el Conqueridor"h, Barcelona 1918, p. 470 .

${ }^{16}$ ACA, C, r.40, f. 64 . 
signaren el pacte ${ }^{17}$. Salvat l'escull de les lluites de la Unió, en les quals Pere es posá de la banda dels nobles, se'l veu actuar decididament contra l'enemic comú, el francès. Els francesos entraren per Navarra i, des d'Estella, l'estiu del 1283, semblava que es disposaven a atacar directament Aragó. Els nobles i cavallers foren convocats a Eixea per tal d'organitzar la resistència; amb ells hi aniria Pere, a les ordres de l'infant Alfons. Des d'Eixea anirien tots, després, a ajudar el rei, que preparava la lluita en un altre indret. Però els nobles no respongueren ${ }^{18}$.

Les tensions entre el rei $i$ els nobles aragonesos venien de molt lluny i s'havien anat agreujant per moltes raons. Tampoc ara no ens hi endinsarem. Ens interessa, però, d'assenyalar la posició de Pere d'Ayerbe pel que fa a la seva relació amb els sobirans. Els nobles s'havien juramentat per tal de defensar els seus privilegis i, reunits a Saragossa l'octubre de 1283, es donaren, entre ells, castells i viles en penyora de la fermesa dels seus propòsits. Pere d'Ayerbe, que figurava com un dels quatre nobles principals de la Unió, donà el castell d'Agüero i fou nomenat conservador per la sobrejunteria de $\mathrm{Jaca}^{19}$.

Aixi i tot, el rei Pere li confià ben aviat una missió especial. En un moment del procés suscitat entre el bisbe i capítol d'Osca, d'una part, i els jurats i alguns habitants, clergues i laics, de la ciutat que havien ocupat béns d'aquells, aquesta part contrària al bisbe prometé donar una seguretat a favor d'ell i restituirli allò que li havia estat pres. El rei envià Pere d'Ayerbe a Osca, el novembre del 1284 , per rebre aquella seguretat. Pere es trobà amb grans dificultats perquè els oficials de la ciutat no ajudaren a facilitar-li la tasca. I de tota manera, malgrat la insistència reial, no es pogué assolir l'objectiu proposat ${ }^{20}$.

17 ACA, C, perg. Pere II, 241. Zurita, Anales, 11. IV, c.11. Id., Indices, pp. $165-166$.

${ }^{18}$ ACA, C, r.61, f.191; r.46, f.101v; r.62, f.6v. L. GonzAlez Antón, Las Uniones aragonesas y las cortes del reino (1283-1301), Saragossa 1975, I, p. 63; II, p. 113 , doc. 21 .

${ }^{19}$ Zurma, "Anales", 11. IV, cc.38, 39. Gonzalez Antón, op. cit., I, pp. 103, 108.

20 J.A. MАRtinez B^RА, «Proceso de don Jaime Sarroca y su cabildo contra algunos clérigos, varios ciudadanos oscenses y su concejo ante la justicia 
Però altres motius aviat van distreure l'atenció del rei més poderosament. L'enemic amenaçava ara directament la frontera catalana. Pere II, el gener del 1285, començà a convocar els seus súbdits per impedir l'entrada dels francesos. D'altra banda, el problema navarrès l'obligava a insistir en la reunió de les tropes d'Aragó a Eixea, mentre que les catalanes el seguien cap a Figueres. I precisament aquí, on el perill era més gran, els aragonesos també li fallaren. Només s'hi presentaren el bisbe d'Osca i Pere d'Ayerbe, el qual es distingi en les accions guerreres del coll de Panissars i del dia de la Mare de Déu d'agost ${ }^{21}$.

En començar el regnat d'Alfons II, Pere d'Ayerbe fou mitjancer en la treva amb els navarresos. La Unió, bé que reduïda en nombre de juramentats, continuava oposant-se a la politica reial. Pere i el seu germà Jaume eren els principals d'entre els unionistes. L'actuació dels dos germans no és mai ben diàfana i potser això és comprensible. D'una banda, la seva condició de rics homes els portava a seguir el moviment i els interessos d'aquella classe social; de l'altra, se sentien lligats pel parentiu amb la casa reial i els devia ser difícil de mantenir sempre una actitud obertament rebel. Pere, el 1288, apareix a l'Empordà, al servei d'Alfons II, en la guerra contra el rei de Mallorca. L'any següent figurava com a membre del consell reial posat per la Unió i, en nom també del seu germà, assessorava el rei en les qüestions amb els unionistes ${ }^{22}$. Poc després, feia testament.

real, VII Congreso de Historia de la Corona de Aragón, III, Barcelona 1964, pp. 49-60. Jaume Sarroca, bisbe d'Osca, era fill de Pere de Rege; fill bastard, aquest, del rei Pere I. Aquest lligam familiar ajuda a explicar l'interès de Pere II a protegir els drets del seu cosí, que ho era també de Pere d'Ayerbe. (J. TrenCHs, «Jaume Sarroca y la escribania de Jaime I», X Congreso de Historia de la Corona de Aragón, 111, Saragossa 1982, pp. 607-621).

${ }^{21} \mathrm{ACA}, \mathrm{C}, \mathrm{r.43}, \mathrm{f} .108 ;$ r.56, ff.84, 92v. ZuritA, "Anales», 11. IV, c.65. B. Descrot, Crónica, caps. 148, 157, 159 (Les Quatre Grans Cròniques, Barcelona 1971 , pp. $547,560,566,569,655,657)$.

${ }^{22}$ Zurita, «Anales», 11. IV, c.79, 82, 83, 91, 93, 99, 108. Id., Indices, p. 199. Gonzalez Anton, op. cit., I, p. 408. 


\section{LA FAMÍLIA DE PERE (I)}

Pere d'Ayerbe mori molt jove, segurament abans dels trentacinc anys. En tot cas, ja no vivia el 6 d'octubre de 1291. Era encara un infant quan el seu pare tractà el seu futur matrimoni amb Dolça, filla de Jaume de Cervera i de Gueraua de Montcada, senyors de Gebut i de Meià. El rei, el 28-IV-1268, reconeixia que havia de pagar 40.000 sous jaquesos que havia promès per a quan es fessin les noces. Aquesta suma fou pagada en terminis successius. El 12-X-1271, Jaume I confessava que només devia 8.000 sous i els assignava a Jaume de Cervera sobre el tribut dels jueus de Lleida; el matrimoni encara no s'havia realitzat. La cessió del dret reial sobre la totalitat de la suma, la féu el rei al seu fill el 27-II-1276, perquè havia mort Jaume de Cervera. Les noces, llavors, ja eren fetes; i podria ser que datessin del 1275, quan Pere rebé les heretats lliures abans esmentades ${ }^{23}$.

Vers la fi del 1279 o el gener de 1280 mori Teresa Gil de Vidaurre. El seu testament, del qual es conserva només un trasllat, és datable, sense certesa però, el 1278. Teresa fa esment de la seva nora Dolça, a la qual deixa tota la roba que ella, la testadora, tingui dins la casa d'Ayerbe. Ens reservem també per a una altra ocasió un comentari més llarg d'aquest testament. Fixemnos tan sols en el que fa referència a Pere d'Ayerbe. Totes aqueJles possessions que li hem vist confirmades devia tenir-les en comú amb la seva mare, per tal com ella les hi deixa com a herència: Cabañas i Azuer, Boquiñeni que ella havia comprat, així com Rosel, Luesia, Agüero i l'heretat d'Ayerbe; no queda clar si volia dir una heretat dins la vila o si es tractava del castell $i$ vila com a totalitat. La condició era que Pere donés 200 morabetins d'or a la seva filla Teresa, quan aquesta tingués edat suficient. També determinava, la testadora, la successió mútua entre els seus dos fills en cas que un d'ells morís sense descendència legítima. I en cas que, de tots dos, no en quedés més que descendència il-legítima, indicava la distribució que caldria fer dels seus béns immobles. A Pere, encara, li era encomanat de donar

${ }^{23}$ ACA, C, r.192, f.23; r.14, ff.96, 129; r.20, f.323v. Miret, op. cit., pp. 410, $456,529$. 
100 morabetins a un Sanç, nét de Teresa (per raó d'un matrimoni anterior) i de procurar que fos clergue $^{24}$.

Per establir la descendència completa de Pere (I) ens caldria haver vist el seu testament, datat, sembla, el 1290; segons un inventari de documents de la casa de Monteada, del qual parlarem, hauria estat datat segons l'era de 1327 i d'això en resultaria l'any 1289 . Els manuscrits que el citen li atribueixen dos fills, efectivament documentats, un altre en posició menys clara i dues filles sobre les quals es mostren molt insegurs. Aixi, uns diuen que les filles foren Blanca i Toda Pérez. Un altre diu que Blanca fou la filla gran i que la petita fou Teresa Pérez, i atribueix a aquesta la familia que els anteriors donaven a Toda. Sobre aquestes lleus bases i amb l'ajut dels documents, tractarem de donar la nostra versióo ${ }^{25}$.

Pere (I) i Dolça es casaren el 1275. El testament de Teresa Gil de Vidaurre pot ser del 1278 i parla de la néta Teresa. Aquesta, doncs, no podia tenir més de dos anys. Si era la gran, és probable que el germà que la seguia fos Pere (II); si el gran era ell, quasi forçosament ella era la segona. No podem creure que l'hagués precedit Blanca, fins i tot per raó del nom, segurament imposat en honor a l'àvia. Tampoc l'àvia no parla de cap altra filla de Pere, si bé ací hauria pogut tractar-se d'una predilecció per la seva homònima.

Deixant a part els altres fills, la segona filla no podia ser altra que Constança. Tenim una sola notícia de la seva existència. Quan

24 Arxiu del Regne de València, Real Justicia, t.805, f.277v.

${ }^{25}$ Ens referim a tres manuscrits que donen noticies de la familia Ayerbe. No els podem donar una fe absoluta fins a comprovar-ne la base documental. Per abreujar, els distingirem per A), B) i C). El que citem com a primer manuscrit pertany a l'obra de Jerónimo de Blancas De los linajes de Aragón (BRAH [Biblioteca de la Real Acemia de la Historia], Colección Salazar, C-148). El segon és una de les còpies del Nobiliario de P. Garcés de Cariñena (Biblioteca Nacional, Madrid, Ms.11.304) i copia ell mateix, pel que fa als Ayerbe, el text de l'anterior, de tal manera que a la fi (fol.137) diu: «Hasta aqui Blancas»; per tant, és difícil trobar-hi alguna novetat. El tercer manuscrit (BRAH, Col. Salazar, B-26, part 7) té un aspecte anònim, potser és obra đe Luis de Salazar, i recull les dades de les obres de Zurita i d'altres historiadors dels segles xvi-xvII. Sobre el testament i els fills de Pere (I): A), f.8-8v; B), f.134-134v; C), f.197v-201. 
Pere i Ximèn Cornel reconegueren Carles de Valois com a rei d'Aragó, desitjosos de veure's exclosos de l'excomunió papal, lliuraren en ostatges dues noies: una filla de Pere i l' «esposa», potser la promesa, de Ximèn, Constança, filla del difunt Pere d'Ayerbe. Era el 14 de novembre de 1291. Tant si era promesa com ja casada, Constança havia d'haver nascut vers el 1279-128026.

La tercera filla ja podia ser Blanca i la quarta, en tot cas, seria Toda Pérez, esmentada en el testament de Blanca mateixa.

Teresa Pérez d'Ayerbe apareix, ja el 1303, casada amb el senescal Guillem de Montcada, senyor de Fraga, vidu de Beatriu de Ventimiglia. El seu dot no havia estat pagat encara el 1310, quan es féu un acord entre el seu marit i el seu germà Pere (II), casat amb la germana de la difunta Beatriu, pel qual aquest cedia els seus drets a la restitució del dot de Beatriu per raons hereditàries, per una suma equivalent a la que ell havia de lliurar a Guillem pel dot de Teresa. Guillem assegurà a la muller 15.000 morabetins d'or sobre les rendes de Fraga. La mare d'ella, Dolça, li assignà la llegítima sobre les rendes d'Alòs i Meià i fins i tot li afegi 100.000 sous barc. sobre les mateixes rendes, que ella $s^{7}$ havia reservat $i$ destinava a sufragis per la seva pròpia ànima ${ }^{27}$. Sembla que Teresa necessità la intervenció del rei, el 1317, per poder cobrar les seves assignacions. En efecte, Alòs, Meià i Baldomar havien estat permutats per Pere (II) amb el rei $i$ es tenien per desobligats de tot $^{28}$. Teresa figura en diversos documents, sola o amb el seu marit, tenint cura dels afers del seu patrimoni, almenys fins al 1321. Aquell any fou empresonada per Guillem, acusada, probablement, d'adulteri. La infanta Blanca, priora de Sixena, moguda pels seus bons impulsos i per l'afecte familiar, volgué intervenir per defensar-la. Però el rei Jaume, després de recomanar-li cautela, li ho prohibí obertament perquè les acusacions li semblaven ben fonamentades ${ }^{29}$. Teresa no va

${ }^{26}$ Archivo General de Navarra, Comptos, Caj. 4, núm. 88. Gonzalez AN. TON, op. cit., II, p. 443, doc. 305.

${ }^{27}$ ACA, C, perg. Alfons III, 266, referències 5,7 i 9; c.r. (cartes reials) Jaume II, 13601; r.597, f.15.

${ }^{28}$ ACA, C, perg. Jaume II, 3537; c.r. Jaume II, 5078.

29 J.E. Martinez Ferrando, "Jaime II de Aragón. Su vida familiar», II, Barcelona 1948, doc. 359, 360. (ACA, C, r.246, f.249v, dos docs.). 
viure gaire més. El 2 de desembre de 1328, al convent de frares menors de Lleida, davant el batlle general de Catalunya, fou oberta una caixa que la difunta Teresa havia dipositat en el convent de les menoretes. Labadessa la lliurà, tancada i sense clau, al rei $\mathrm{i}$ aquest l'envià als frares $\mathrm{i}$ ordenà que l'obrissin. A dins hi havia catorze documents en pergamí, referents a Teresa i la seva familia, i d'ells en fou fet un inventari somer. És una llàstima que en l'acta que en dóna testimoni no hi hagi els resums complets dels documents ${ }^{30}$.

Guillem i Teresa tingueren tres filles. La primera fou Margarida, a la qual el seu pare féu donació de Fraga el 1320 en casarse ella amb Artal de Luna. La seva mare li donà, per dot i part de llegítima, 60.000 sous, part dels seus 15.000 morabetins. Però Margarida no en cobrà res i en el seu testament disposà que Fraga fos venuda i que, del preu, els marmessors en retinguessin la suma del dot; el 1338 encara no l'havien rebuda. Vidua el 1324, Margarida fou objecte de la protecció reial el 1329 i morí abans del 30-I-1332, data en la qual el rei ordenava l'embarg dels seus béns per tal d'atendre la reclamació d'uns drets de les seves germanes. Eren, aquestes, Teresa, successivament senyora de Fraga, que es casà amb Ot de Montcada el Jove; i Blanqueta, que fou la muller de Guerau de Cervelló, fill de Guillem, vers el $1335^{31}$.

La tercera filla de Pere (I) d'Ayerbe, Blanca, es casà amb Ferran López de Luna, senyor de Lurcenich, Chodes i Arándiga, fill, probablement, de Lope Ferrenc de Luna, procurador general d'Aragó. El matrimoni fou concertat per aquest, però Lope morí, abans del 1304, sense veure'l realitzat. Calculem que se celebrà vers aquella data ${ }^{32}$. El 1307 , Blanca feia una reclamació al rei sobre la tinència del castell de Santa Maria d'Albarrassí. La retrobem el 1318, quan insta per l'alliberament de la seva

${ }^{30} \mathrm{ACA}, \mathrm{C}$, pergs. Alfons III, 266. El pergamí conté una breu referència a cadascun dels catorze documents de la casa de Montcada.

31 ACA, C, r.218, f.88v; r.478, f.203v; r.534, f.53; r.597, f.15; r.885, f.121.

${ }^{32}$ Devem, i agraim ben sincerament, moltes de les noticies relacionades amb la casa de Luna al doctor Francesc de Moxó. Citem, en els llocs corresponents, les planes de la seva obra inèdita «La casa de Luna. Factor político y lazos 
mare, que García Pérez d'Ayerbe tenia detinguda injustament ${ }^{33}$. Ja vidua abans del setembre de 1320 , hagué de lluitar per tal de recuperar, per sentència arbitral, els llocs de Chodes i Arándiga que tenia obligats pel dot. El 6-II-1322, el rei li atorgà la seva protecció, a ella i a la seva filla, Aldonça Fernández, de la qual ella volia actuar com a tutora, especialment en un plet sobre els termes de Chodes, el 1325. Però com que no havia prestat jurament ni donat fiadors, la tutela no li fou encara reconeguda. És curiós que en aquests anys no es parli del fill de Blanca, citat, segons que sembla, en el testament d'ella. El rei, el 1326, es queixava de Blanca perquè ella s'havia avançat a fer justícia corporal contra un súbdit seu d'Arándiga, en lesió de la jurisdicció reial per certes raons ${ }^{34}$.

Els manuscrits antics parlen del testament de Blanca, datat el 26 de novembre de 1331, i diuen que es trobava al monestir de Predicadors de Saragossa; ella volgué la seva sepultura al convent de les Predicadores, amb altres dames de la familia ${ }^{35}$. Però, dels manuscrits, no en coneixem el text original i això ens suscita una sèrie de dubtes força difícils de resoldre. En primer lloc, diuen que ella parla de dos fills, Lope i Aldonça Fernández de Luna; no obstant, el fill hauria mort, solter, abans que la mare, i potser no hi hauria error si ella hagués viscut un temps després del testament, cosa que ignorem. Aldonça restà com a hereva universal de la seva casa. Promesa a Joan Ximénez d'Urrea ja el 1330 i, més tard, potser, a Guillem, duc d'Atenes, fou al centre d'una llarga discussió entre les cases de Luna i d'Urrea, que tal vegada hauria acabat amb la realització del primer matrimoni, si el jove Joan no hagués caigut víctima de les lluites

de sangre en la ascensión de un linaje aragonés (1276-1348)», Madrid 1984. Sobre el matrimoni de Blanca d'Ayerbe: t.I, pp. 22 i 96, i nota 201 del cap. II.

${ }^{33}$ ACA, C, c.r. Jaume II, 3071; r.165, ff. $234,234 \mathrm{v}$.

${ }^{34}$ ACA, C, r.170, f.198v; r.221, f.167v; r.186, f.110; c.r. Jaume II, 9006. Mo. xó, op. cit., II, doc. 155.

${ }^{35}$ BRAH, A), f.8-8v; C), f.200v-201; BN, B), f.134-134v; Moxó, op. cit., I, 22, 96. J. BAucells, «La infanta griega Láscara y sus hijas Beatriz y Violante, aragonesas de elección”, La ciudad de Zaragoza en la Corona de Aragón. X Congreso de Historia de la Corona de Aragón, Saragossa 1984, pp. 75, 79. 
de la Unió, el 1348; i suposant que Aldonça, ja de salut més aviat feble, no hagués mort abans que ell ${ }^{16}$.

Segons els manuscrits, el tutor d'Aldonça havia de ser Palacin de Cervera, cosí de Blanca. Si Dolça de Cervera constava sempre com a filla única, difícilment podia tractar-se d'un cosí germà, llevat que fos per línia il-legitima.

Però encara hi ha dubtes d'una major categoria. Diuen que Blanca féu un llegat a la seva neboda Blanqueta, filla de la seva germana Toda Pérez i de Jaume de Cervera. El més explícit diu que Jaume era fill dels senyors d'Algerri, Ramon (germà del pare de Dolça) i Berenguera de Pinós; que Blanqueta es casà amb Bertran de Fenollet, fill segon de Pere i d'Esclarmunda de Canet; que la filla d'ella, Esclarmunda, es casà amb el vescomte Felip Dalmau de Rocabertí i no deixà successión ${ }^{37}$. Els documents, però, no sembla que hi estiguin d'acord. Comencem per Esclarmunda de Fenollet, vescomtessa de Rocabertí, menor d'edat el 1348, en morir el seu pare, i ja adulta i casada, el 1356. Deixant de banda l'esment, també del 1348, d'una Marquesa, filla de Bertran i hereva universal de la mare, la difunta Robertona, que ens fa imaginar un error de nom o una desaparició seva immediata, resta un testimoni del 1380: Esclarmunda, la vescomtessa, que es declara hereva de la seva mare Robertona i del difunt Robert de Bellveí, sense indicar parentiu, reclama els comptes de la seva antiga tutoria. Això demostraria que la mare no fou Blanqueta i que el cognom de la vescomtessa era, probablement, Bellvei ${ }^{38}$.

Segons els arbres publicats de la casa de Cervera, ja que no disposem d'altres documents, un Ramon de Cervera, senyor d'Algerri, casat amb Miracle d'Urgell tingué, entre els seus fills, Jaume, senyor de Meià i pare de Dolça; i Guerau, que fou senyor d'Algerri. D'altra banda, a l'arbre dels Pinós, hi figura certament una Berenguera casada amb Ramon de Cervera i morta

${ }^{36}$ Moxo, op. cit., I, pp. 22, 25, 26, 27, 96 i nota 106 del cap. I.

${ }^{37}$ BRAH, C), f.201.

${ }^{38}$ ACA, C, r.1413, f.75v; r.1415, ff.16, 26v; r.898, f.112; r.1412, f.130; r.1441, f.131. 
després del $1277^{39}$. Hi ha la possibilitat que aquest Ramon i Guerau fossin una mateixa persona i que el matrimoni tingués un fill, Jaume, que no figura, per ara, enlloc més. I encara: el 1314 havia ja mort la senyora d'Algerri, Esclarmunda de Cervera. Els seus marmessors, entre els quals, en primer terme, hi havia Ot de Montcada el Vell, conservaren les possessions i tingueren per elles un plet amb Berenguer d'Anglesola. Guillem de Montcada, el senescal, els pagava 60.000 sous jaq. a les darreries del 1316. Qui era Esclarmunda? Creiem que només podia ser filla de Guerau (Ramon) o bé muller del suposat Jaume, i en darrer cas, filla i hereva d'aquest; ella, sempre, sense descendents. El 1319, Guillem de Montcada feia un debitori de 200.000 sous jaq. a la seva muller Teresa per raó de la venda del castell $i$ vila d'Algerri ${ }^{40}$. Potser Teresa seria també entre els marmessors? Era realment Esclarmunda una Ayerbe, o potser una Montcada? De tota manera, a l'espera d'un futur aclariment, veiem com Toda Pérez d'Ayerbe se'ns va allunyant de la realitat. I la legatària de Blanca ens va semblant cada vegada més que fou Blanqueta de Montcada, la filla de Teresa.

Tornem ara als fills de Pere (I). El segon d'ells fou Jaume. És ben poc el que n'hem pogut saber. Fou un dels candidats, proposat per Jaume II, al matrimoni amb Giovanna, filla i hereva de Nino Visconti, jutge de Gallura a Sardenya, i de Beatriu d'Este. L'interès del rei era d'impedir les noces d'ella amb algú que fos favorable als pisans, ja que es tractava de minar l'autoritat d'aquests sobre l'illa amb la perspectiva de la futura conquesta pels catalano-aragonesos. Però la proposició arribà tard, les noces prengueren una altra direcció i Jaume no arribà mai a casar-se, ni amb Giovanna ni amb ningú més ${ }^{4}$. Heretà, en vida de la se-

${ }^{39}$ GEC (Gran Enciclopedia Catalana), v.5, Barcelona 1973, pp. 40-42; v.11, Barcelona 1978, p. 601.

${ }^{40}$ ACA, C, r.211, f.236v; r.161, f.59v; perg. Alfons III, 266, referències 4 i 2. Segons Zurim (Anales, II. III, c.54), Ramon, germà de Jaume i casat amb Berenguera; tingueren una filla que fou Esclarmunda, senyora d'Algerri. Això exclouria la filiació de Jaume i el seu matrimoni amb Toda. No obstant, un Jaume de Cervera aparcix durant els plets de Dolça, la vidua de Pere (I) d'Ayerbe. Si es casà amb Toda, podria haver estat el seu primer marit.

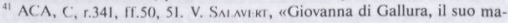


va mare, el dret a les possessions d'ella a Catalunya i això donà lloc a un plet entre ells, que probablement ell no veié acabat. Féu testament el 24 d'agost de 1308, a Saragossa ${ }^{42}$. Volgué la seva sepultura a l'església de Sant Pere d'Ayerbe, prop de la del seu pare. Féu hereu, del dret sobre els castells i viles de Catalunya, el seu germà Pere, amb l'obligació de pagar tots els seus llegats. Aquests, tret de 50 sous a un Ferrandiello no identificat, eren per a tres dames, per tal que es poguessin casar: Maria Gil, de Luesia; Joana de Bizcarra, d'Ayerbe; i Estevania de Lobera. La primera era la mare d'una filla de Jaume, Teresa, a la qual ell deixava, per dotar-la, 500 morabetins d'or que, si no es casava, tornarien a l'hereu del testador. El termini fixat a Pere (II) era d'un any, menys el llegat de la jove Teresa, que es pagaria en el moment de les seves noces. Si Pere no pagava, el seu dret passaria al cosí Jaume de Xèrica, a qui era donat el termini d'un altre any; i passat aquest, si no s'havien complert les condicions, el rei heretaria el dret, amb mig any més de temps per complirles. En darrer cas, els marmessors vendrien el dret per tal de pagar els llegats. Jaume d'Ayerbe mori, amb tota seguretat, el mateix any del testament.

Pere (I) tingué un tercer fill, Garci Pérez d'Ayerbe, la legitimitat del qual és del tot insegura. El segon Pere, en el seu testament, el cita com a senyor de Rosel i li llega 20.000 sous. Segons Blancas, era bastard. L'autor del tercer manuscrit sembla apuntar la possibilitat d'haver recollit, Garcia, l'herència dels seus dos germans; però diríem que, si ho féu, no fou com a hereu sinó en nom de l'hereva universal ${ }^{43}$. Diu Muntaner que Garcia anà amb la Companyia Catalana a Orient i que, el 1306, fou un dels comissionats per la mateixa Companyia per anar a demanar socors al papa Climent V i a Carles de Valois en favor

trimonio e la politica sarda di Giacomo II d'Aragona", Archivio Storico Sardo, XXIV, Cagliari 1953, pp. 20-21.

${ }^{42}$ BRAH, A), ff.11v-12; C), f.200.-BN, B), ff.136v-137. Zurra, Anales, 11. V, c.69. Existeix un trasllat, fet a Saragossa el 9-I-1309, de les disposicions testamentàries de Jaume: ACA, C, Papers per incorporar (en curs de classificació), caixa 21 , núm. 7 (prov.).

${ }^{43}$ BRAH, A), f.8; C), ff. 200-200v. 
de Berenguer d'Entença; el resultat fou negatiu ${ }^{4}$. El 1310, el rei li donà, com a mainaderia, a canvi de servir amb tres cavalls armats, 1.500 sous jaq. anuals: 750 , assignats sobre la reial tresoreria i 750 , sobre les salines de Nabal; reduïdes ambdues quantitats, respectivament, a 500 sous, els 500 restants foren assignats sobre les salines de Castellar i Remolins. Revocada aquesta concessió el 1318, fou renovada de la forma esmentada en segon lloc, el 1321; però al marge hi fou anotat: «decessit». Aquesta nota devia ser força posterior, per tal com Garcia visqué almenys fins al 1323. En parlarem més endavant ${ }^{45}$.

La vídua del primer Pere d'Ayerbe, Dolça, sobrevisquẻ a tots els seus fills. Tingué llargs conflictes per raó de les seves heretats. Fa la impressió d'haver estat una dama difícil de tracte; fins $i$ tot sembla que els del seu entorn fessin el possible per tenir-la allunyada, a vegades com si els resultés incòmoda.

Des del seu matrimoni, vers el 1275 , i el testament de la seva sogra, vers el 1278, en perdem el rastre fins al 3-VII-1305, quan el rei ordena pagar-li un deute de 400 sous barc. Però seguidament li fa un préstec de deu mil sous barc. més; en canvi, ella feia un debitori amb obligació dels seus llocs $\mathrm{i}$ castells, l'herència del seu pare a Catalunya ${ }^{46}$. Precisament apareix en aquests dos documents amb el que en podríem dir el seu nom de solte$\mathrm{ra}$, tal vegada perquè es referien al patrimoni de la casa paterna. Resulta curiós, si pensem que no solament era vídua d'Ayerbe, sinó que també sembla que era vídua de Luna. En efecte, aixi ho afirmen alguns estudiosos i sembla corroborar-ho un altre document, de l'agost del 1306, pel qual el rei feia remissió d'unes penes de terç per raó de deutes, fins al valor de 400 sous jaq., a Aldonça, vídua de Lope Ferrenc de Luna. Hom diu que es tracta de la mateixa Dolça, que hauria estat la segona muller de Lope, el procurador general d'Aragó, el qual havia mort ja abans d'acabar el 1304. És molt possible que el matrimoni sigui

44 ACA, C, c.r. Jaume II, 9888. A. Ruнo, Lıен, Diplomatari de l'Orient Català, Barcelona 1947, pp. 28-29, doc. XXIII. R. Muntaner, Crònica, c. CCXXIX (Les Quatre grans Cròniques, p. 986).

45 ACA, C, r. 313, f.153v; r.314, ff.177, $177 v$.

${ }^{46}$ ACA, C, r.295, ff.11, 14. 
cert, si bé no en tenim, fins ara, proves més clares; un indici més podria ser el fet que el document esmentat anés adreçat al veguer $\mathrm{i}$ cort de Lleida, ciutat on Dolça tingué, de vídua, el seu domicili ${ }^{47}$.

Un parent de Dolça, Pere Arnau de Cervera, fou encarregat de tenir els castells (Alòs, Meià, etc.) com a castlà, en nom del rei, fins que ella retornés el préstec. Al mateix temps, ella devia també diners a un draper de Lleida, Llorenç de Timor. I malgrat que havia obtingut del rei una pròroga temporal, el sotsveguer de Camarasa i els seus homes, manats pel veguer de Lleida, havien pres bestiar del castell d'Alòs per pagar el deute ${ }^{48}$.

Però la qüestió de fons devia ser una altra. El testament de Pere (I) havia resultat conflictiu. Havia deixat al fill gran les possessions aragoneses $\mathrm{i}$ al petit, les catalenes en concepte, una mica recercat, de restitució del dot matern. A la mare li deixava l'usdefruit vitalici. Dolça, de moment, es mostrà d'acord, però després devien venir les desavinences amb els fills. El rei, per alguna raó, volia que Dolça li lliurés els llocs de Catalunya a canvi d'altres donacions. Assignà el cas, com a jutge, a Ombert de Capdepont, un estranger, amic de Pere (II) i, per tant, vist amb desconfiança per Dolça; i més perquè ja hi havia un altre jutge encarregat del plet: Ramon d'Anglesola, bisbe de Vic. Un grup de juristes reunits a Lleida opinà que ella no podia ser obligada a alienar les seves propietats, si bé de dret podia fer-ho, perquè hauria perjudicat els fills. Finalment s'anaren inclinant en favor de la viabilitat de la permuta ${ }^{49}$. Mentre ho decidien, el rei prestà 40.000 sous barc. a Dolça i ella li empenyorà els castells, sobre els quals ja tenia hipoteca pels 10.000 sous del préstec anterior; però li fou prohibit d'atansar-se a les seves terres fins a retornar el que devia ${ }^{50}$.

Mentrestant, els castells continuaven embargats, per més que ella reclamava i s'oferia a pagar el deute. El bisbe de Vic i Pere Arnau de Cervera la convenceren d'anar ajornant les seves re-

47 ACA, C, r.203, f.187. Moxo, op. cit., II, p. 89, doc. 79.

48 ACA, C, c.r., Jaume II, sense data, 1144, 1584.

49 ACA, C, c.r., Jaume II, sense data, 51, 1850, 1015.

so ACA, C, c.r., Jaume II, 3023; sense data, 1888. 
clamacions a l'espera del conveni amb el rei, mentre un escrivà li feia dir quins valors esperava rebre si es feia la permuta. Dolca, feta l'estima de les seves terres, demanava rendes equivalents i, a més, 20.000 sous barc. Calia, però, que es fes l'estima del que el rei pensava donar-li, i això s'anava allargant ${ }^{51}$. Dolça no es cansava d'escriure al rei, queixosa de les dilacions. Vivia a Lleida, amb pocs mitjans, sense poder disposar dels seus castells, i es mostrava seriosa quan donava pressa al rei perquè, deia, «asats de trebayll e sofert en la vostra triga». Insistia d'anar personalment a veure'l i explicar-li els seus problemes, però Pere Arnau la deturà fins que es rebessin noves ordres reials sobre el fet ${ }^{52}$.

Enmig de les incidències d'aquesta qüestió, cal situar-hi el plet entre Dolça i el seu fill Jaume sobre els mateixos castells d'Alòs i Meià. El rei volia encarregar-lo a Pere, bisbe de Lleida, però aquest s'excusà tot al-legant que era cosí germà de Pere (I) i que dubtava del dret de Jaume. Els germans Ayerbe i Guillem de Montcada anaren a demanar auxili al comte d'Urgell, tement que el rei finalment afavoriria la part de Dolça, però el comte no es volgué indisposar amb el rei i no accedí al que ells volien. Jaume II insistí, el juliol del 1308, per tal que el bisbe acceptés la comissió de la causa i el bisbe tornà a excusar-se, dient que no veia clara la intensitat del desig del rei ${ }^{53}$.

La permuta havia estat acordada el 1307. Dolça volia que li donessin terres que no fossin prop del Segre. Però vingué la mort de Jaume $\mathrm{i}$ el plet degué restar suspès ${ }^{54}$. Aci ens trobem amb una llacuna que, per ara, no podem salvar. Les següents notícies de la permuta són del febrer del 1311 i els tractes es porten directament entre el rei i Pere d'Ayerbe. Aquest donava els castells i llocs de Vilanova de Meià, Alòs, Fontllonga, Castelló de Meià, Baldomar, la Nou, Fabregada, la Maçana, Enet, Castelló d'Orenga, Vernet, Argentera, Clusa, Cabrera, Mulnar, Peralva,

51 ACA, C, c.r., Jaume II, 10388, 13579, 11531, 2694, 2614; sense data, 181, $1701,1648,1891$.

${ }^{52}$ ACA, C, c.r., Jaume II, 2935, 12869; sense data, 171, 978.

${ }^{53}$ ACA, C, c.r., Jaume II, 11594, 11599, 12837, 3540.

54 ACA, C, c.r., Jaume II, 2935. 
Muntroy i Menia. I rebia els de Robres, Grañén, Pradilla, El Frago, Javierregay, Biel, vall de Pintano, La Peña, Lobera, Urries, Escó, Sales de Suso i Sales de Juso (Salas Altas i Salas Bajas). El canvi, finalment, es realitzà el 14-IV-1312. De fet, a més dels llocs aragonesos i el seu mer i mixt imperi, el rei donà 130.000 sous jaq. i 58.000 sous barc. per si els llocs catalans tenien més valor. $\mathrm{A}$ aquests darrers els fou promesa la inseparabilitat de la corona. Tot això fou possible perquè Dolça, el 18-I-1312, havia fet donació perpètua dels llocs al seu fill gran. Els creditors lleidatans d'ella es feren sentir per reclamar al rei el que se'ls devia. El rei s'havia de fer càrrec de totes les qüestions pendents referents als llocs intercanviats ${ }^{55}$.

Al cap d'uns deu anys, Dolça era encara presa de preocupacions econòmiques. El seu fill Pere, ara ja difunt, a l'època de la permuta li havia assignat 3.000 sous jaq. anuals vitalicis i li obligà tots els seus béns, especialment els llocs de Sales de Suso i Sales de Juso. Després el mateix Pere vengué els llocs i la concessió fou transferida sobre les rendes d'Ayerbe. L'assignació no fou mai pagada i el rei, que n'havia estat fiador, el 12-III-1323 ordenà als marmessors de Pere que complissin com era degut. D'altra banda, el justícia d'Aragó, fent cas dels creditors de Dolça, i sense considerar la moratòria per un any que ella havia obtingut, li embargà els drets que tenia sobre els béns del seu fill $\mathrm{i}$ que devien comprendre l'assignació esmentada. Calgué també que elrei li ho fes desembargar i encarregués al justícia la resolució dels plets que Dolça volia moure als marmessors per tots els perjudicis que havia rebut; ells s'haurien d'atendre a la sentència. El 15 d'abril el rei els manà que venguessin els béns de Pere per poder pagar i el 9 de juny els deia que tinguéssin cura de la paga anual de l'assignació pels habitats d'Ayerbe, però fou tot inútil. Finalment, el primer de juliol de 1324, encarregà als jurats i habitants d'Ayerbe que fossin ells els qui paguessin directament Dolça, dels diners que solien donar als marmessors ${ }^{56}$.

55 ACA, C, r. 209, ff.13lv, 14lv, 178v, 180; r.210, f.77v; Varia, v.297, f.94 (ara 45).

56 ACA, C, r.302, f.29v; r.182, f.204v; c.r. Jaume II, 6969, 6970, 6971, 6972, 6973. 
Mentrestant, Dolça, que ja devia tenir més de seixanta anys, pensava donar una nova orientació a la seva vida. I decidia d'ingressar en el monestir de les Menoretes de Saragossa. El rei se'n mostrà complagut i gosariem dir que se'n sentí alleujat. Ignorem, però, si ella arribà a entrar al convent $i$, més encara, si arribà a professar-hi. El 18-VII-1335, l'infant Pere, el futur Pere III, atorgava la seva protecció a Dolça i a la seva casa i béns. També ell s'hagué de preocupar per la situació econòmica de la dama. Essent ja rei, el 1338, prohibí als seus oficials d'entrar a la casa d'ella i d'embargar-li béns mobles o utensilis per tal de pagar deutes als seus creditors. No obstant, això no impedia que Pere III procurés que Dolça li cedís tots els drets que tenia contra els marmessors del seu fill i les persones que tenien béns d'ell, especialment els qui li havien de pagar 310.000 sous jaq. que li havia adjudicat el justícia d'Aragó. Aquests drets, l'11-III-1345, el rei els donà a la seva muller, la reina Maria, per subvenir a les seves despeses; tot i retenir 40.000 sous per pagar les gestions judicials. No ens consta documentalment si Dolça vivia encara; no és impossible. En tot cas, com ja dèiem, ella fou una de les grans supervivents de tota la seva família ${ }^{57}$.

\section{PERE (II) D'AYERBE}

Fou el fill gran, i hereu, de Pere (I). Quan aquest morí, ell era encara menor d'edat; li calculem uns quinze anys escassos. A més d'algunes cavalleries que heretà del seu pare, en rebé d'Alfons II sobre l'alcaidia de Saragossa i en tingué també sobre les aljames de sarraïns d'aquesta ciutat i de Torrellas, i sobre Pina i Ariza. Però no hi podia comptar gaire, perquè els llocs eren pobres i a vegades obtenien exempcions, bé que fossin temporals, com en el cas de Grañén i Robres, o també el de Ruesta, adquirit el 1300. El total de les cavalleries de Pere, el 1302, era el següent: dues a Ruesta, sis a Ariza més quatre sobre la peita del lloc, dues sobre l'alcaldia de Saragossa i quatre sobre la mo-

${ }^{57}$ ACA, C, c.r., Jaume II, 7331; r.576, f.140; r.865, f.154v; r.1523, f.172. 
reria, tretze sobre Taraçona, exclosos els jueus i els sarraïns, una a Longares i Ibarduese sense la peita, una a Castellazo. I per completar el nombre de cinquanta, en cobrava dues en diners dels sarraïns i quinze del tresor reial. Aquestes disset darreres, que no responien a cap realitat en terres, havien de transformars'hi a mesura que altres terres quedessin a disposició del rei. Grañén i Robres, el 1304, passaren a poder d'un tercer, a qui el rei encomanà el pagament d'una suma a Pere pel dot de la seva muller, obligada sobre les rendes d'aquells $1 \operatorname{locs}^{58}$.

Per totes aquestes cavalleries, Pere prestava el corresponent servei reial. En un cert moment, quan el rei, el 1305, es disposava a anar a la cort pontifícia, admetia Pere en el seu seguici i l'esperava a Girona. El senyor d'Ayerbe es trobava a Eixea i li calia dur a terme els seus preparatius. Com que tenia por de no arribar a temps, pregava al rei, si aquest començava a passar endavant, que li deixés indicat el camí que prendria, per tal d'anar a reunir-se amb ell així que li fos possible. Val a dir que Pere tenia altres motius per estar prop del rei. Havia estat nomenat majordom reial d'Aragó, ja abans del 1301, i consta que ho era encara el juny del 1306. El salari, però, sempre li fou pagat amb retard 59 .

L'estiu del 1307 corregué el rumor que Pere d'Ayerbe, així com els seus cosins Jaume de Xèrica i Pere Fernández d'Híxar, pensava presentar-se a la cort amb cavalls i armes, com en actitud bel-licosa. El rei els preguntà per escrit si allò era cert i ells s'apressaren a respondre que la seva intenció era de servir-lo i que l'anada a la cort no tindria res de desacostumat; és més, Pere deia que no hi anirien sense que el rei els ho manés. Segons ells, eren víctimes del recel d'algú que no volia el seu bé. Al cap d'un any, els tres cosins, des de Montalbà, enviaven un nunci al rei per exposar-li un assumpte que no li podien dir per carta. Ignorem de què es tractava però creiem que podia referir-se tot al mateix rumor $^{60}$.

${ }^{58}$ ACA, C. r.192, f. $23 ;$ r. 255, f.22v; r. 312 , ff. $25,25 v ;$ r. 199, f. $.77 ;$ r. 313 , f.16; r. 314, f.26; r. 202, f.195v.

${ }^{59}$ ACA, C, c.r., Jaume II, 2486, 2165; r.294, ff. $24 v, 25,189$.

${ }^{60}$ ACA, C, c.r., Jaume II, 12266, 9586, 3591. 
L'amistat amb Pere Fernández d'Híxar no podia ser gaire antiga. Aquest, per raons que també ignorem, desfià el seu cosí. El rei li ordenà que retirés el desafiament, i la seva resposta no deixa de ser curiosa. Hixar havia estat greument malalt, i, l'octubre del 1305, encara no s'havia restablert del tot. Això també el duia a complir el manament reial, però feia notar que, per més que obeiria, hauria preferit que el rei no li ho hagués manat. El seu ressentiment devia ser considerable ${ }^{61}$.

Com el seu pare, el segon senyor d'Ayerbe intervingué en molts afers de la més alta importància. Ja de petit, el 1287, Pere (I) l'havia donat en ostatge durant les qüestions dels unionistes; i també quan s'uní amb els Cornel en proposar que Carles d'Anjou fos rei d'Aragó ${ }^{62}$. Fou convocat a la campanya de Múrcia, el 1300 , i a les lluites contra la Unió, així com a les corts de Saragossa $(1300-1301)^{63}$. Probablement havia estat ell el senyor d'Ayerbe que assistí a la coronació de Jaume II, el $1291^{64}$. Fou un dels que s'obligaren, el 1296, a guardar el tracte entre el rei i l'infant Juan Manuel, en el setge d'Elx ${ }^{65}$. I també, el 1308, un dels que juraren fidelitat i homenatge a Ferran IV de Castella quan fou signat el contracte matrimonial de la filla d'aquest, Elionor, amb l'infant Jaume, primogènit d'Aragó ${ }^{66}$. Després d'assistir al jurament dels privilegis per l'infant a les corts de Saragossa, el 1311, l'actuació pública de Pere es va reduint a qüestions relacionades amb les seves possessions: des d'un plet amb els jueus d'Osca sobre usures, a un altre plet amb Ferran de Luna sobre els termes de Luesia, a començaments del $1318^{67}$. A Pere li restava ja poc temps de vida.

61 ACA, C, c.r., Jaume II, 2519.

62 Zurits, «Anales", 11. IV, c.91. Gonzalez Anton, op. cit., II, pp. 223, 367.

63 ACA, C, r.332, ff. 57, 73-73v, 199-200, 212. González Antón, op. cit., II, pp. 493-494, 501-502, 548-549, 556.

64 Zurita, "Anales», 11. IV, c.123.

65 ZuritA, "Anales», 11, V, c.21. F. Cascales, Discursos históricos de la muy noble y muy leal ciudad de Murcia, Murcia 1775, p. 77.

66 J. MiReti Sans, "El forassenyat primogènit de Jaume IIn, Memòries de la secció històrico-arqueològica XVIII, Institut d'Estudis Catalans, Barcelona 1957 , p. 11.

${ }^{67}$ ACA, C, c.r., Jaume II, 4385; r.164, f.242. 
Aquest Pere també havia de morir força jove; segurament no va passar dels quaranta-tres anys. La seva vida matrimonial fou bastant inquieta. Gairebé adolescent, es casà amb Maria Fernández de Luna, filla de Lope Ferrenc de Luna. Fos perquè no arribava la descendència que ell desitjava o perquè se li hagués presentat una avinentesa millor, el fet és que Pere abandonà la muller tot al-legant que ella era menor d'edat. L'excusa, de moment, li fou acceptada, el matrimoni fou anul-lat i pogué casarse novament, vers el 1298 , amb una dama de més alt llinatge: Violant de Grècia ${ }^{68}$.

Violant era la quarta filla de Guillem de Ventimiglia i d'Eudòxia Làscaris, filla aquesta de Teodor II i néta de l'emperador grec de Bizanci, Joan Dukas Vatatza. Eudòxia, coneguda ací com la infanta Làscara, arribà amb els seus cinc fills a la cort catalanoaragonesa entre el $1275 \mathrm{i}$ el 1277 , seguint les passes de la seva àvia entenada, l'emperadriu vidua Constança Hohenstaufen. Violant havia nascut el $1270^{69}$; era, doncs, una mica més gran que el seu marit. Devia ser una dama intel-ligent $\mathrm{i}$ bon xic emprenedora. El 1301, actuant en nom de la seva mare, ja havia venut el castell de Moixent, que ella tenia en feu reial, a Gonçal Garcia $^{70}$. De fet, ella fou, de les quatre germanes, la qui rebé l'herència materna. La germana segona, Beatriu, s'havia casat amb Guillem de Montcada, senyor de Fraga, el 1282; féu testament el 1295 i morí vers el 1300, sense descendència $a^{71}$. Havia disposat la seva sepultura en el lloc on l'escollís la seva mare; Làscara, que morí el 1308, l'escollí al monestir de Predicadores de Saragossa. Lany següent, Violant obtingué la llicència per traslladar-hi les despulles de Beatriu des de la seu de Lleida, on romanien provisòriament. La seva intervenció era doblement justificada, per tal com Làscara havia estat l'hereva de la seva filla

68 ACA, C, r.196, f.193. Moxó, op. cit., I, p. 95.

${ }^{69}$ Zurita, "Anales», 11. V, c.105. Baucells, op. cit., pp. 65, 68.

${ }^{70} \mathrm{ACA}, \mathrm{C}, \mathrm{r} .198, \mathrm{f} .307 \mathrm{v}$.

${ }^{7}$ ACA, C, r.55, ff.1-2v; cr. Jaume II, 1268. Baucells, op. cit., p. 66. És del 1300 la concessió d'una suma que el rei li donava graciosament. 
Beatriu. El 10-II-1310, Violant féu un acord amb el seu cunyat Guillem (també doblement cunyat, ara com a marit de Teresa d'Ayerbe), pel qual ella cedia el seu dret a mil marcs d'argent que ell havia rebut com a dot de Beatriu; pagada una part per afers pendents d'aquesta, el restant passava al rei i a Pere d'Ayerbe per tal d'acabar de pagar el dot de Teresa, mentre Jaume II s'obligava a pagar a Violant la part que a ell li toqués ${ }^{72}$.

Les activitats de Violant l'havien duta a continuar la tasca de l'emperadriu Constança, la qual, en el palau reial de València, havia establert una mena d'escola per a l'educació de les infantes. En morir ella, el 1307, Violant s'encarregà aviat de la mateixa missió. Entre les deixebles, a més de les filles de Jaume II, hi figurava Elionor de Castella, la promesa de l'infant Jaume, des del $1312^{73}$.

El primer de desembre de 1310, Jaume II vengué a Violant, en alou, 5.000 sous barc. anuals sobre les rendes i peita de Berbegal. L'assignació li fou permutada amb les rendes de Llíria, el 18-XII-1312. Ella tenia por de sortir-hi perdent $\mathrm{i}$ havia pregat al rei de retardar la permuta, però a l'últim hi consentí. En aquells moments es trobava convalescent d'una greu malaltia. La permuta, doncs, tingué efecte i fou notificada als jurats i prohoms de la vila el 23-II-1313. Violant restitui al rei les rendes de Llíria el 23-VII-1317, probablemnt a conseqüència de la venda en alou que li féu el rei, el mateix dia, del castell de Tibi i torre de Torraçela, i de l'alqueria de Sarganella, prop de Castalla, així com de l'alqueria de Vinaloba i el lloc de Benifalim, terme de Penàguila, per 18.000 sous barc. $^{74}$

El matrimoni de Pere d'Ayerbe i Violant acabà amb una separació. El 1312, el rei intervenia personalment en la qüestió, com

${ }^{72}$ ACA, C, r.143, f. 257; c.r. Jaume II, 13601. BAuceus, op, cit., pp. 66, 73, $74,79$.

${ }^{73}$ Buncelıs, op. cit, pp. 70-71. Id. "L'expansió catalana, fou vehicle d'irradiació cultural?m, Segundo Congreso Internacional de Estudios sobre las Culturas del Mediterráneo Occidental. Trabajos teidos en Barcelona, 1975. Barcelona 1978, p. 261.

${ }^{74}$ ACA, C, r.207, f.212v; r.210, f.14; r.240, f.157; r.214, ff.78, 79v; r.259, f.140v; perg. Jaume II, 2791. BNuCELLS, La infanta cit., p. 71. 
testimonien les cartes que rebia de Violant. Martí, bisbe d'Osca, pronuncià la sentència de divorci el 1313, després de set anys de separació de fet. La causa al-legada fou l'existència de l'anterior lligam de Pere que algú no havia considerat anul-lat, i perquè Maria Fernández de Luna encara era viva, si bé casada amb Pere Fernández d'Híxar. Les dues filles de Violant foren, però, declarades legitimes, donant per certa la bona fe en el matrimoni dels seus pares ${ }^{75}$. Si Pere tenia la residència oficial a Ayerbe, Violant residia a València i altres ciutats, seguint més o menys la cort. De la residència de les filles, no en tenim una certesa absoluta. El 14-VII-1315, el rei mostra la seva disconformitat amb el projecte de Violant d'enviar la filla gran, Constança, a la casa de la infanta Elionor de Castella. Després es repensà i, un any més tard, ho veia amb bons ulls i li permetia d'estar-hi des del setembre fins a Tots Sants. Per la seva banda, Pere projectava el matrimoni d'una filla seva, segurament Constança, per al qual, el 6-XI-1317, el rei li atorgà 2.000 morabetins d'or sobre les demandes que es fessin a les universitats $i$ aljames de jueus de Calataiud, Daroca i Terol ${ }^{76}$. Els projectes no arribaren a terme i Pere no cobrà aquella quantitat.

Pere d'Ayerbe preparava un viatge a França i, com solia fer-se en casos d'un viatge llarg, féu abans el seu testament, a Luesia, el 14 de juny de $1318^{77}$. Volia ser soterrat a l'església de sant Pere, d'Ayerbe, i que s'hi fes una nova capella dedicada a santa Maria, on reposarien les seves despulles i hi serien portades les del seu pare i el seu germà Jaume. L'hereva universal seria Constança, i aci retrobem Garcia Pérez, senyor de Rosel, que esdevindria el seu tutor i la tindria en el castell d'Ayerbe fins que es casés, aconsellada per ell i pel rei. Ella, però, no podia ser senyora d'Ayerbe per raó de les substitucions per línia masculina imposades en el testament del rei Jaume I. Tampoc no devia ser-ho Garcia, que figura sempre com alcaid del castell. A l'al-

75 ACA, C, c.r., Jaume II, 12904, 13174. Zurita, Anales, 11. V, c.105. Bau CELLS, La infanta cit., p. 68.

${ }^{76}$ ACA, C, r.254, f.189; r.277, f. $240 v ;$ r.259, f. 19.

77 ACA, C, r.245, f.12v. BRAH, A), f.9v; C), f.198v-BN, B), f.135. BNuCELL, La infanta cit., p. 69. 
tra filla, Maria, li tocaven els castells de Grañén i Robres, les rendes dels quals, durant quatre anys, servirien per pagar els deutes que Pere hagués deixat; per a aquest fi, també volia que fos venut el lloc de Bureta. Ja havia venut Sales de Suso i Sales de Juso i, com que no podia completar-ho amb possessions, assignava a Maria 80.000 sous sobre el lloc d'Agüero. Si ella moria sense descendència, tot el que tenia seria de Constança. I si cap de les dues no deixava successió, el rei adquiriria Ayerbe, Luesia i Agüero mitjançant 300.000 sous, per complir els testaments de Pere (II) i del seu pare. A Garcia Pérez li deixava 20.000 sous, $i$ altres 3.000 en llegava a la seva mare, Dolça, la qual continuaria vivint a Ayerbe sota la guarda de Garcia. Precisament aquesta disposició fou la que denuncià al rei Blanca Pérez d'Ayerbe, la qual acusava el seu germà de tenir la mare detinguda sense cap raó; Jaume II ordenà el seu alliberament immediat.

Pere (II) tingué cinc fills bastards. Un segon Garci Pérez, la mare del qual fou Mari Beltran de Lihuerre. El seu pare li deixà els llocs de Marcuello, Siurana i Riglos, aquest amb una condició: una germana del testador tenia uns drets a Riglos. Segons un dels manuscrits que hem vist, era Teresa; segons un altre, era Toda Pérez. Si ella o algun hereu seu o de Pere López de Riglos volia recuperar el lloc, hauria de pagar 2.000 morabetins d'or segons un llegat del seu pare. Si no, el lloc quedaria lliure per a $\mathrm{Garcia}^{78}$.

Un altre fill fou Miquel, a qui el seu pare havia donat Liso i Artaso. En el testament revocá la donació i els llocs foren per a l'hereva universal. Sobre les seves rendes, assignava 20.000 sous en concepte d'aixovar a Mari Sánchez, muller de Miquel. A aquest li deixà, en canvi, el dret que tenia sobre Sigues i Escó.

Fou també fill bastard de Pere un Sancho Pérez, que no figura en el testament patern, però sí en el de la seva germana Constança.

De Mari Sánchez de Rasal tingué una filla, Elvira, a la qual el seu pare deixà 7.000 sous perquè es casés.

${ }^{78}$ BRAH, A), f.9v; C), ff.199-199v-BN, B), f. 135. Si es tracta realment de Toda Pérez, podriem creure que el seu marit fou Pere López de Riglos; potser el segon marit, si existí el matrimoni amb Jaume de Cervera. 
Finalment una altra Constança, filla de Pere (II) i de Teresa López, rebria 2.000 sous per entrar en religió.

Pere d'Ayerbe, tal vegada, hagué de renunciar al seu viatge. Morí el 6 de juliol de 1318. El 19 d'agost ja s'havien suscitat els primers problemes a l'entorn de Constança, la seva hereva. Algú tenia interès a fer-se càrrec d'ella. La seva mare, Violant, temia que l'allunyessin de la casa pairal i demanà al rei que fes complir el testament i la lliurés al seu tutor Garcia Pérez d'Ayerbe. Jaume II hi accedí i recomanà a aquest que la tingués ben guardada fins que ell anés personalment a Aragó i veiés el que calia fer $^{79}$.

Els marmessors de Pere foren el seu germà Garcia Pérez i Garcia Gil de Soteras. Fins al 28-IX-1320 el rei no aclari el compte dels deutes de la cort procedents de les cavalleries; el 25 de gener següent ordenà al tresorer que els pagués la suma deguda: en total, 43.994 s. 8 d.jaq. De les 50 cavalleries de Pere, 10 havien estat atorgades al seu cosi Jaume de Xèrica el 27-VIII$1318^{80}$. D'altra banda, el rei feia que paguessin un altre deute, de mainaderia i assignacions endarrerides, a Garcia Pérez d'Ayerbe per un total de 8.615 sous jaq ${ }^{81}$. Garcia fou conseller de l'infant Alfons i el servi amb la seva gent d'armes. L'infant, el 30IV-1321, demanava la intercessió reial prop de la cort de França en favor de Garcia, el qual volia anar a Bascònia o enviar-hi algú per tal de recuperar uns castells de la seva muller i que un noble li havia pres. Una de les darreres notícies de Garcia és l'autorització reial, del 10-VIII-1323, per treure del regne 500 càrregues de blat $^{82}$. El 15 d'abril anterior, els marmessors havien rebut l'ordre de vendre tots els béns de Pere d'Ayerbe; ordre reiterada, per la insistència de Dolça, el primer de juliol de 1324, quan Garcia ja era difunt i havia estat subrogat en lloc d'ell, en la marmessoria, Pere Fernández de Vergua, el 23 de gener del mateix any. Aquest darrer era encara confirmat l'11-II-1338, en morir Gil de Soteras; restava a l'albir de l'abat de Montaragó

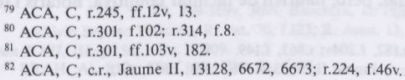


el nomenar-ne un altre ${ }^{83}$. Els marmessors hagueren de lluitar amb la manca de diners per pagar deutes $\mathrm{i}$ injúries, entre elles les que havien rebut del primer Pere els habitants d'Ayerbe, els de Loarre i els d'Almudévar. Tots ells finalment cediren a Alfons, ja rei, a canvi d'unes certes franqueses, els seus drets sobre els béns de la casa d'Ayerbe ${ }^{84}$.

\section{CONSTANÇA D'AYERBE}

La història dels darrers anys de Violant de Grècia va unida a la de la seva filla Constança. La lletra del 19-VIII-1318 que confiava la noia a Garcia Pérez, juntament amb una lletra del justícia d'Aragó, la portà un procurador de Violant, acompanyat d'un notari i testimonis, al castell d'Ayerbe. Des d'allà foren atacats amb pedres i sagetes $i$ hagueren de retrocedir sense presentar les lletres. Violant les féu llegir públicament en el cementiri de la parròquia i en deixà una còpia a la porta de l'església. Ella deia que Garcia havia permès que la noia fos treta del castell. Després, Garcia la recuperà. Així i tot, Jaume II pensava que si Garcia no havia complert com a marmessor, tampoc no compliria el que ell li manés sobre aquest afer. I, autoritzat pel testament de Pere (II) a intervenir-hi, ordenà als seus oficials aragonesos que cerquessin Constança allà on fos, l'acompanyessin al monestir de Sixena amb una bona comitiva i la deixessin al càrrec de la priora. Si els qui la retenien es resistien a lliurar-la, podrien actuar contra d'ells, amb les forces militars si calia. El qui tenia Constança en poder seu era Jaume, senyor de Xèrica, a qui Garcia l'havia encomanada. El 17-XII-1318, el rei li envià Joan Garcés d’Alagón, porter major de l'infant Jaume, per tal de prendre-la i dur-la al monestir, ja que, segons els furs, tenia prou edat per sortir de la tutela. Amb això, el 10 de gener següent, rellevà els oficials del compromís: es limitarien a lliurar Constança a Joan Garcés, al qual, però, haurien de facilitar comitiva, notaris i tot

${ }^{83}$ ACA, C, r.182, f.204v; r.863, f.149.

${ }^{84}$ ACA, C, c.r., Jaume II, 9353; r.476, f.161; r.858, f.62. 
el que ell necessités per dur a terme la seva missió. Més tard, per a major seguretat, ordenava a Garcia Pérez que deixés marxar la noia amb el porter enviat; tal vegada Jaume de Xèrica l'havia tornada al castell ${ }^{85}$.

Al cap de dos mesos, vist que ella havia de casar-se a voluntat reial, Jaume II li trobà fàcilment el marit adequat: el fill gran de Jaume de Xèrica, el futur Jaume (III) del seu llinatge. Efectivament, el 17-III-1319 comunicà la decisió a la futura núvia i la posà sota la custòdia de la que havia de ser la seva sogra, Beatriu de Lloria, dama molt discreta i de vida honesta i lloable; si bé més tard li fou donat d'escollir entre anar a viure amb la seva mare o a un altre lloc. Els marmessors del seu pare restaven encarregats d'induir-la a l'obediència; per tant, Constança hauria de conformar-se a la voluntat reial. Mentre la tenia segura a Xèrica, el rei tramitava la necessària dispensa matrimonial per raó del parentiu dels nuvis i cercava una solució per als tràmits ja començats entre els Xèrica i Artal de Luna per un altre matrimoni del mateix Jaume ${ }^{86}$. La dispensa per tercer grau de consanguinitat fou atorgada pel papa Joan XXII i comunicada al bisbe de València el 21 de gener de $1320^{87}$.

Malgrat tots aquests esforços, el casament no es pogué realitzar. Constança emmalaltí, a Xèrica, i només pensà de fer testament. La data, segons els manuscrits, fou el 22 de novembre de l'era 1359, tres anys més tard que el seu pare; resultaria clarament el $1321^{88}$. Però publiquen només una part del text i d'ací se'n deriven certs dubtes. Després d'escollir la sepultura a l'església de Sant Pere d'Ayerbe, Constança declara hereva universal la seva germana Maria, amb la forma de substitucions disposada pel seu pare i la perspectiva que l'herència passés a la corona. Per tal de complir els llegats testamentaris i acudir als deutes del pare i de l'avi, Constança ordenava la venda dels castells de Cabañas, Azuer, Boquiñeni i Bureta; del que en cobrés,

${ }^{85}$ ACA, C, r. 245, f.12v; r.165, ff.252, 252-253, 253-253v, 266v.

${ }^{86}$ ACA, C, r.339, ff.369, 369-369v, 369v. BAuCELIS, La infanta cit., p. 69.

${ }^{87}$ Archivio Segreto Vaticano, R. Vat. 70, f.123; R. Aven. 13, f.316. Mol.tar, Jean XXII, III, p. 56, núm. 10909.

${ }^{88}$ BRAH, A), f.10v; C), f.198v,-BN, B), f.136. 
el seu marmessor havia de pagar 20.000 sous pels quals es trobaven obligats els llocs de Liso i Artaso (com ja sabem, a la muller de Miquel d'Ayerbe) i, després, aquests llocs quedarien per a ell. El marmessor no era altre que Garcia Pérez. A la filla d'aquest, Teresa, li tocaven 2.000 sous jaq. com a llegat. Un altre Ilegat igual el feia la testadora a la seva germana Constança, així com deixava 3.000 sous al seu germà Sancho Pérez. Un dels interrogants el constitueix un llegat de 3.000 sous Jacobo Petri avunculo meo. Hem vist com Jaume d'Ayerbe havia mort el 1308. No és versemblant que en vida d'ell, Constança, encara infant, hagués pogut fer testament. Ara com ara, la identificació ens resulta impossible. Un altre cas: en disposar l'ordre de substitucions, Constança fa esment de la seva mare i no es pot endevinar per quina raó. Donant per bona la data del testament, la mare ja no vivia. Si en lloc del 1321 hagues estat fet el 22-XI1320 , tampoc. Sense el text original, el problema cronològic resta insoluble.

Violant, aquells darrers anys, ja devia malaltejar. Hi ha noticia d'una estada seva als banys de Caldes de Montbui, el $1318^{89}$. Va morir segurament el 1320. El seu marmessor Martí d'Alfaro, el 20-X-1320, vengué els llocs de Tibi i Sarganella a Ximèn Pérez de Montornés, per 102.000 sous reals. Ximèn li donà una tassa d'argent en penyora del futur pagament total; però després volgué desfer el tracte. El rei manà que es complís una ordre anterior, del 4 de juliol, i es resolgués el cas segons el fur d'Aragó. Al marmessor li quedaren diverses qüestions pendents. Encara, el 1328, l'herència de Violant es trobava involucrada amb la cort $\mathrm{i}$ altres persones per pagaments de deutes ${ }^{90}$.

\section{MARIA D'AYERBE}

La darrera hereva de la casa d'Ayerbe fou Maria, la germana de Constança. No hem pogut saber com foren els primers anys

\footnotetext{
${ }^{89}$ Baucelts, La infanta cit., p. 71.

${ }^{90}$ ACA, C, r.170, f.229; r.492, f.163v; r.259, f.205; r.302, f.98v; c.r. Jaume II, 7334.
} 
de la seva vida. Hem vist com el seu pare li deixà els llocs de Grañén i Robres, i 80.000 sous sobre Agüero. I la seva germana, segons el tercer manuscrit, li hauria deixat els de Cabañas, Azuer i Boquiñeni, si bé també hem vist que calia vendre'ls i potser fou aquesta la vertadera disposició.

El 15-V-1324 apareix casada amb Pere Cornel, senyor d'Alfajarín. És quan reclama perquè el marmessor de Pere (II), Garcia Gil Soteras, s'ha retingut els llocs patrimonials per tal de pagar les esmenes per injúries. En queden només 250 sous jaq. anuals. Ella vol que siguin assignats 8.000 sous jaq. anuals al pagament per injúries i que els llocs es desembarguin. El justícia d'Aragó $i$ un jurisperit d'Osca foren encarregats de fer l'acord amb els marmessors i de lliurar els llocs a Maria, bo i recordant-li que, si venia el cas, que ella no tingués descendència, es complirien les substitucions testamentàries i els llocs passarien al rei. Al mateix temps, el matrimoni Cornel feia un conveni amb l'infant Alfons sobre la casa i terres d'Ayerbe: si Alfons vol que ells tinguin la casa desembargada, ells assignaran uns rèdits anuals als marmessors de Pere (II) per tal de complir el seu testament; en cas contrari, que Alfons vulgui retenir Ayerbe, cal donar altres llocs o rèdits als Cornel. Si tampoc no els vol donar, la casa $\mathrm{i}$ els llocs els seran desembargats però ells pagaran anualment per les antigues injúries, tret del que era degut als homes d'Almudévar, Loarre, Bolea, La Perdiguera i altres, als quals Pere (I) havia causat danys en temps de guerra $i$ ells havien cedit els seus drets a l'infant Alfons. D'aci, el dret d'aquest a la casa d'Ayerbe, a part de les substitucions testamentàries. Per tant, els Cornel s'obligarien a tenir tota la baronia excepte Agüero, per a l'infant o per al rei, i a no fer mai guerra contra la casa d'Aragó, a la qual tornaria el patrimoni si no quedava descendència familiar; els hereus de Maria, en aquest cas, tindrien la baronia fins que fossin pagats tots els deutes $i$ injúries ${ }^{91}$.

Sempre segons el tercer manuscrit, la vila d'Ayerbe passà a la corona en morir García Pérez, últim fill legítim, diu, de la

91 ACA, C, r.182, f.95; c.r. Jaume II, sense data, 261. Bauceuts, La infanta cit., p. 69. 
família. Això vindria de la disposició de Jaume I, continuada en els testaments dels titulars, de seguir la línia masculina. Maria no podia ser la senyora titular de la baronia, malgrat que en fos l'hereva familiar. Alfons III devia conservar-la, doncs, o tal vegada Maria li vengué la jurisdicció, i el 1329 la cedí en alou a la seva muller Elionor $i$ als fills d'ella. Els altres llocs, seguint aquell mateix testament reial, passaren a la casa de Xèrica. Maria, però, continuava titulant-se senyora d'Ayerbe. Davant la protesta dels procuradors de la reina, Pere Cornel s'hi oposà, el 23IV-1336, com a defensor dels drets de la muller ${ }^{92}$. Pere Cornel mori durant les guerres de la Unió, en temps de Pere III.

De Maria és conegut el fet que, el 1331, a Grañén, rebé la reclamació d'una suma que tenien assignada les monges Predicadores de Saragossa. Ella respongué que calia cercar els béns de la seva àvia Làscara per pagar-ho, però, de béns, ja no n'hi havia. Ella envià al mateix monestir el seu testament i també un codicil donat a Osca el 7-XI-1348. Volia la sepultura prop de les dames de la seva família. I sembla que fou a Osca on morí, força vella i sense descendència, el $1386^{93}$.

Així acabà la línia familiar legítima. Però no acaben del tot els nostres dubtes. Mentre la senyoria d'Ayerbe, ja al segle xv, havia passat a la casa d'Urríes, la successió familiar, legítima o no, s'havia anat conservant. El tercer manuscrit parla dels antecessors dels prínceps de Cassano, els quals es deien descendents de la familia a partir d'un Miquel d'Ayerbe; i apunta que també podrien pertànyer a una altra família de cavallers d'aquest nom, que no sembla que tingués cap relació amb la dels nobles. Doncs, bé: quan la baronia s'incorporà a la corona, sembla també que el rei cedí a un dels nobles Ayerbe, segurament a Miquel, la senyoria de Paternoy; d'aquí hauria sortit, en efecte, la família italiana. Miquel no podia ser altre que el fill bastard de Pere (II) ${ }^{94}$.

Existeix una breu correspondència entre un dels membres de

${ }^{92}$ BRAH, C), ff. 201-201v.-ACA, C, r.1532, f.41v; perg. Pere III, 20. BaUCELLS, La infanta cit., p. 69.

93 BAuCels, La infanta cit., pp. 69, 74, 75.

94 BRAH, C), f. 199v. GEC, v.11, p. 361. 
la branca italiana, Filibert d'Aragó i Ayerbe, príncep de Cassano, i Hipólito Samper, un valencià que exercí alts càrrecs a l'època de Carles II. Samper, vers els anys 1676/77, havia escrit alguns llibres, el més famós dels quals era, potser, Montesa ilustrada, i es disposava, per encàrrec del príncep, a escriure la biografia de la que ells anomenaven «santa reina», Teresa Gil de Vidaurre. Per això demanava algunes dades familiars al príncep, el qual li feia un resum genealògic dels seus orígens, al mateix temps que li manifestava la seva particular visió de la història de la familia. La llàstima és que, si bé afirma que la seva casa és l'única descendent del rei Jaume I, cita com a antecessor més llunyà Sanç d'Ayerbe, oficial i acompanyant d'Alfons el Magnànim a Itàlia i fundador de la branca; però sense enllaçar-lo amb la familia reial. La seva genealogia no concorda exactament amb la que coneixem dels senyors de Paternoy, però no es tracta ara d'esbrinar quina és la més fidedigna. Ens interessa només fer constar que l'emperador Carles I, el 1519, erigí el comtat de Simari, a Calàbria, en favor d'Alfons d'Ayerbe, fill de Sanç, cuius progenitores antiquissima stirpe Aragonum regum inicium habuerunt $t^{9}$. Si ell ho diu, l'ascendència és certa. Però si l'enllaç s'estableix amb Miquel d'Ayerbe, no podem deixar de pensar que la línia era il-legitima d'origen, mentre algun nou document no ens demostri el contrari.

${ }^{95}$ BRAH, Col. Salazar, E-5, ff.201-202, 203-205, 206-209v, 210-210v. ACA, C, r.3932. f.142. 


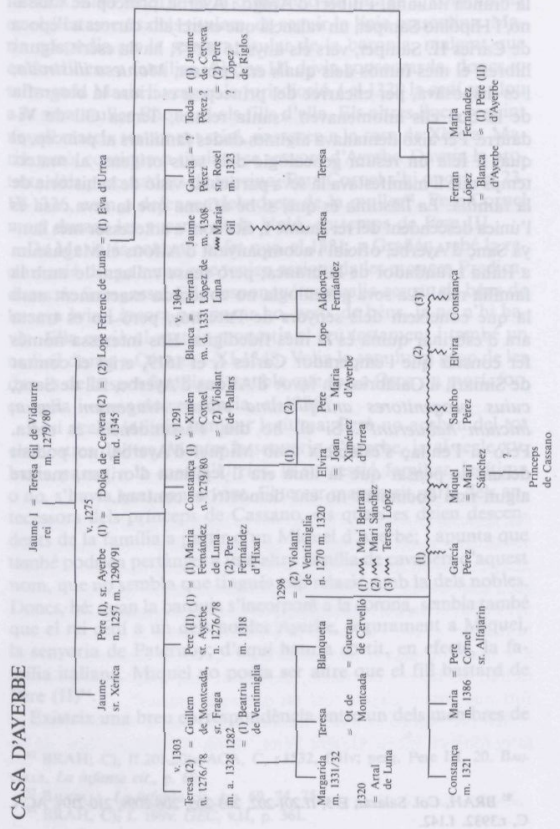

